\title{
ANDRÉS SÁNCHEZ ROBAYNA, LATITUDES AMERICANAS
}

\author{
Gustavo GUERRERO \\ Université de Cergy-Pontoise/Paris Seine \\ Institut d'Etudes Politiques de Saint-Germain-en-Laye
}

$\mathrm{E}$ n 1994, en un artículo publicado en el Anuario del Instituto de Estudios Canarios, Andrés Sánchez Robayna revisa un capítulo de la historia literaria del archipiélago, discurriendo sobre el aporte de tres escritores nacidos en las islas a la formación de la cultura colonial americana. Siguiendo un estricto orden cronológico, analiza, en primer lugar, el caso del jesuita y poeta tinerfeño José de Anchieta (1534-1597), quien desarrolló una amplia labor misionera y catequista en Brasil; luego, se ocupa del grancanario Silvestre de Balboa (1593-1640), vecino de la ciudad de Camagüey, en Cuba, donde escribió su famosa epopeya Espejo de Paciencia (1608); y, por último, cierra con tres párrafos dedicados al erudito palmero Pedro Álvarez de Lugo (1628-1706), un curioso letrado que, desde su provincia, se erigió en uno de los principales lectores y comentaristas contemporáneos del Primero Sueño (1692) de Sor Juana Inés de la Cruz (Sánchez Robayna, 1994: 49-60).

No voy a detenerme a glosar detalladamente los precisos apuntes con que, en aquel artículo, Sánchez Robayna nos muestra la importancia de estas tres figuras en la temprana génesis de una cierta sensibilidad literaria americana. Baste subrayar con cuánto énfasis destaca el papel fundacional que desempeñaron y, en particular, las preguntas que plantea -que no puede dejar de plantear- la rápida e inusual identificación de los dos primeros con las realidades de América. «¿Cómo fue esto posible - se exclama-, cómo dos escritores nacidos en Canarias -José de Anchieta y Silvestre de Balboa- lograron identificarse de la manera tan intensa en que lo hicieron con el espíritu de las culturas americanas?» (Sánchez Robayna, 1994: 56). La elaborada respuesta que él mismo nos ofrece a renglón seguido, y que vale la pena citar in extenso, combina persuasivamente argumentos históricos, literarios y psicológicos; pero, sobre todo, tiene la virtud de ofrecernos, a mi modo de ver, un utilísimo testimonio para empezar a describir la posición del propio Sánchez Robayna, como poeta canario, ante América:

Como ha subrayado Paul Lunde, los indígenas canarios fueron el primer pueblo 'primitivo' que encontraron los europeos en los tiempos modernos. Es dable pensar que tanto en José de Anchieta como en Silvestre de Balboa había una suerte de memoria histórica de sus orígenes (bien cercanos, por otra parte) y que ello pesara tanto en su forma mentís como en su comportamiento. Lo que sentían y experimentaban 


\section{Gustavo Guerrero}

ante las situaciones encontradas en el Nuevo Mundo, ¿no era, en verdad, lo que sentían acerca de su propia genealogía cultural? La conquista de Canarias -se ha dicho- fue para los europeos un 'estímulo' para salir en busca de «otras islas que se decía estaban hacia el oeste», según recuerda Lunde. El fabuloso y súbito ensanchamiento de los límites de Occidente que se produjo con el Descubrimiento ya había comenzado con la conquista de Canarias. Y hay que recordar -dentro, aún, de la 'continuidad histórica' aludida- que la definitiva incorporación del archipiélago a la corona de Castilla es posterior a la fecha del Descubrimiento. En cuanto a Canarias y a América, todo era, pues, historia reciente, y hasta, en gran parte, historia simultánea. Nuestras islas eran ya en cierto modo el Nuevo Mundo, como dirán todavía, en fechas muy posteriores a las que aquí estamos viendo, varios escritores y viajeros, incluyendo a Alejandro de Humboldt, que decían hallarse entre nosotros ya fuera de Europa, y dentro, en cambio, de un nuevo espacio geográfico y cultural. No en vano, los historiadores afirman que el moderno 'redescubrimiento' europeo de las Islas Canarias fijó las pautas para la conquista, la colonización y la explotación económica de los primeros territorios americanos encontrados, las islas caribeñas. No de otro modo cabría entender, acaso, cómo la experiencia de 'aclimatación' fue en esos escritores algo asumido con naturalidad: en el caso de Anchieta en Brasil y de Balboa en Cuba, se diría que ambos ya formaban parte de la latitud americana antes de llegar al Nuevo Continente (Sánchez Robayna, 1994: 57-59).

Cuando se recorre la bibliografía y, en especial, los artículos, diarios y entrevistas de Sánchez Robayna, no es difícil comprobar que son numerosos los pasajes en que vuelve sobre esta proximidad e, incluso, sobre esta familiaridad que, desde sus inicios, caracteriza la relación de la cultura canaria con América (Sánchez Robayna, 2002: 148-154; 2005: 27; Arjona, 2009). Existe, sin lugar a dudas, un vínculo especial, una afinidad profunda que no solo es producto de la ubicación de un archipiélago que, durante cuatro siglos, fue la primera escala en la ruta de las flotas y una vasta encrucijada del tráfico marítimo (y de tantos otros tráficos) entre las dos orillas del Atlántico. Además, como lo recuerda nuestro poeta, en la historia de Occidente, las Canarias constituyen ese laboratorio de ensayo donde se ponen a prueba por primera vez los modelos militares, económicos, sociales y políticos que le dan una forma a la colonización europea. La cultura de las islas nace y crece en la estela de esta experiencia colonial, marcada por un sentir de la novedad y la diferencia, de la excentricidad y la sujeción, que la emparenta estrechamente con la alteridad americana y genera (y sigue generando) análogas tensiones con los centros metropolitanos europeos y sus proyectos de modernidad (Merediz, 2009). Canarias es, en este sentido, un territorio de frontera y una finis terrae: allí termina el mundo conocido y allí empieza lo ignoto, como lo constató Humboldt. O dicho en otras palabras: allí terminan las mil descripciones que una cultura fabrica para garantizar a diario el sentido de nuestro vivir, y allí empiezan los silencios y los desajustes entre palabras, cosas y experiencias, la necesidad de un lenguaje otro para decir aquello que escapa al ámbito familiar de lo que se nombra.

Desde el siglo XV, las islas comparten con América esta condición de confín que tanto atrae y maravilla a los viajeros, pero cuya cara oscura (en el fondo, la misma) es la posición asimétrica, periférica y marginal que ocupan y que representa, hoy por hoy, una metáfora del plúmbeo legado del colonialismo descrito por el concepto de colonialidad (Mignolo, 2003; Quijano, 2007). Lo que con él se nos recuerda es que los modos del crear y del conocer (y sus productos) no han gozado siempre del mismo valor ni de las mismas posibilidades de circulación (lo uno por lo otro), según se ubiquen en la cercanía o la lejanía de los centros metropolitanos. De ahí que, al igual que en América, en Canarias uno de los principales rasgos que definen el quehacer cultural en los tiempos 
modernos, sea la busca de una buena distancia desde la cual se puedan administrar crítica y creativamente las relaciones con esta pesada herencia y con las formas de dominación contemporánea que aún secreta en el plano axiológico, cognitivo y simbólico.

Situados dentro de esta perspectiva, los numerosos y apretados lazos que la obra de Sánchez Robayna teje con el mundo americano bien pueden ser interpretados como parte de un proyecto poético y político, individual y colectivo, que busca simultáneamente en la realidad canaria y en su vocación atlántica, las materias y los patrones necesarios para componer, desde la lontananza, una obra singular, autónoma y dialogante, una obra capaz de apropiarse críticamente de su pasado y de generar asimismo espacios para defender el ideal de un cosmopolitismo plural y descentrado. Creo que es más interesante leer el vínculo del poeta con América en esta clave postcolonial que en la que nos propone el viejo discurso de la Hispanidad y su reivindicación de la unidad de las literaturas de lengua española, un tópico que también aparece en Sánchez Robayna (2005), como en tantos autores latinoamericanos recientes y menos recientes. Y es que no solo la irreductible originalidad de la poesía del canario, sino asimismo las polémicas y las controversias que suscitaron sus posturas críticas en los años noventa y dos mil, en especial tras la publicación de la antología Las ínsulas extrañas (2002), nos hablan del afán de postular el principio de un lenguaje radicalmente distinto y, con él, una modernidad alternativa que no se reduzca a la del solo meridiano de los centros hegemónicos aunque no deje de conversar y también de enfrentarse con ellos (Rojo, 2002; SánchezRobayna, 2005). En más de un sentido, de dicho forcejeo se ha nutrido a través del tiempo el impresionante árbol que Sánchez Robayna ha ido alzando con su obra durante ya casi medio siglo. Para examinarlo a cabalidad harían falta muchas horas de estudio y muchas páginas; pero acaso sea posible acercarse a sus raíces (y a su arqueología) dentro de los límites de un corto ensayo como este, si, dejando de lado la vana ambición de hacer un inventario de todos los autores latinoamericanos con los que mantiene un comercio intenso y continuo, concentramos más bien nuestra atención en las tres figuras mayores que presiden a su biblioteca atlántica. Aquí volvemos a encontrarnos con Cuba, México y Brasil, pero, esta vez, a través de las densas y estratégicas lecturas que el canario hace de los escritos de José Lezama Lima (1910-1976), Octavio Paz (1914-1998) y Haroldo de Campos (1929-2003).

\section{José Lezama Lima: de una teleología insular}

La presencia de Lezama Lima es, sin lugar a duda, capital en la teoría y la práctica de la poesía con que Sánchez Robayna se va dando a conocer a lo largo de los años setenta y ochenta. Tanto es así que libros como Clima (1972-1976), Tinta (1978-1979) y La roca (1980-1983), las piezas centrales de su primer período, no se entienden del todo si se omite la referencia a las ideas del cubano sobre la condición insular y la especial teleología que, según él, la acompaña. Recordemos que, en los años treinta, en las páginas de su Coloquio con Juan Ramón Jiménez (1937), Lezama Lima esboza una interpretación de la crisis de la nación cubana a partir de una toma de conciencia 
del problema de la insularidad, no como un dato geográfico, sino como un asunto de historia cultural y de caracterización de una cierta subjetividad. Lo insular, opuesto a lo continental o incluso a las culturas de tierra adentro, se viviría en Cuba como una experiencia de la excentricidad, la lejanía y el desarraigo que haría de la isla una suerte de barco extraviado a merced de los vientos y le impediría escapar de su pasado e identificarse con un destino. Tal y como señala Arnaldo Cruz-Malavé en su estudio ya clásico, El primitivo implorante (1994), Lezama Lima recurre a la vieja noción cristiana de teleología para transformar esta visión pesimista de la historia en la raíz de un nuevo mito fundacional: para el poeta habanero, habría un sentido preservado y secreto que, desde sus inicios, rodea a la cultura insular cubana de un halo trascendente y cuyo desciframiento traduciría el enigma de su epifanía. «Se trata de escapar a la cadena unívoca de la tradición y al desplazamiento desarraigado de la historia -agrega Cruz-Malavé- instalándose en los orígenes mismos de la creación»(Cruz-Malavé, 1994: 34). Es más: «Contra el peso de la tradición y la historia que subordina o limita las posibilidades de creación de lo moderno y lo americano, Lezama propone este mito del insularismo: un sistema poético total cuyo objeto es convertir la marginación en centro» (Cruz-Malavé, 1994: 35).

Sánchez Robayna encuentra así muy temprano en Lezama Lima no solo una reflexión sobre la especificidad de la condición insular, sino todo un programa que ve en las islas una reminiscencia del momento inicial de la creación y el trasunto mejor del enigma que se cifra en la palabra de la poesía. El mismo lo explica, con una precisión y una claridad admirables, en una conferencia que imparte en la Universidad de Austin, Texas, en noviembre de 1984:

La epifanía del poema guarda una misteriosa relación con aquello que la suscita. Cité más arriba la idea de una teleología de lo insular debida a José Lezama Lima. Quiero citar ahora otras palabras suyas que, más que definir esta idea, la vuelven una imagen. «Lo epifánico - escribe Lezama- parece estar en el madreporario de las islas, que han de ser redescubiertas por una exigencia de la imagen». Pues bien, desde un principio, desde los primeros poemas de Clima hasta los más recientes de La roca, me vi interrogando el espacio insular, indagando el sentido o el destino de lo insular como una forma concreta de realización de la cultura, esto es, como forma poética, como un modo de conocimiento y como una raíz espiritual; un irrenunciable modo insular, en fin, de estar en el mundo, un modo de habitar una imagen del mundo. El poema se me ofrecía entonces bajo el enigmático signo de la pura respiración insular, según el modo antiguo de una concepción de la poesía como variación mítica, el platónico hacer mito (Fedón, 61B). Tal sería, en efecto, la forma última esencial no solo de esta formulación de la insularidad, sino de la poesía misma (Sánchez Robayna, 1999: 192-193).

Lejos del inventario y la tentación descriptiva, los versos de Sánchez Robayna se acercan al paisaje y a la geografía de las islas desde esta perspectiva mítica y avanzan en pos de un sentido oculto cuya revelación (cuya epifanía) exige un lenguaje otro, ni realista ni mucho menos exótico. Muy al contrario, el tipo de extrañeza del que quieren asentar un testimonio, se sitúa más bien en las antípodas de cualquier exotismo, pues constituye una forma de subversión del mismo y de sus presupuestos históricos: digamos que es el intento por erigir el espacio insular en un nuevo eje del mundo a través de un viaje genesiaco que nos devuelva al primer momento de la creación, al doble origen del verbo y de lo real. De ahí que lo físico adquiera constantemente una vocación metafísica y espiritual al enunciarse en una poesía singularísima, de un rigor geométrico y a menudo abstracto 
con el que se aspira a retener no un paisaje sino aquello que esconde y cuyo sentido reverbera incesantemente en su inminencia: los teatrillos ardientes de la isla bajo el sol del mediodía. Ya ha sido dicho que puede verse en la manifiesta fascinación de Sánchez Robayna por la pintura de su paisano José Jorge Oramas, a quien dedica varios textos entusiastas (1999: 211), un equivalente visual de sus propias búsquedas. En cualquier caso, lo esencial es comprobar cómo la invención de este lenguaje otro, ni pintoresco ni tradicionalista, constituye un modo de escapar al lastre del pasado y una reafirmación de la finalidad superior de la poesía ante el extravío de la historia.

A la manera de un puente entre Cuba y Canarias, la teleología insular sitúa a Sánchez Robayna en una de las varias órbitas de Lezama Lima y lo acerca (no podía dejar de acercarlo) a otro de los grandes lectores del maestro habanero: Severo Sarduy. Los artículos y ensayos que el canario dedica a este último y que consagra a la elucidación de su poética neo-barroca, prolongan en muchos momentos su relación con Lezama Lima y, al mismo tiempo, hacen patente el deseo de dibujar, en el ámbito hispánico contemporáneo, la cartografía cultural de una nueva vanguardia atlántica (Sánchez Robayna, 1993: 181-191; 1999: 49-74). La cuestión de la insularidad forma parte de ella y sigue siendo, a través de los años, un tema constante en la escritura de nuestro poeta, sin duda el signo mayor de su anclaje local y su proyección americana. Cuaderno de las islas (2011) da fe de esta continuidad y de la expansión y diseminación del imaginario insular a otros ámbitos de la experiencia, como una poderosa herramienta de exploración poética de las relaciones entre geografía, creación y existencia.

\section{Octavio Paz: de una poesía crítica}

La obra de Octavio Paz constituye asimismo una lectura temprana en los años de formación del canario, como lo atestan las dos breves reseñas que le dedica a fines de los setenta y que se recogen en el libro La luz negra (1985). En ellas comenta la aparición del poema largo Pasado en claro (1975) y luego hace un recorrido por la trayectoria del mexicano entre Ladera Este (1962-1968) y Vuelta (1976), a la sazón de sus publicaciones más recientes (Sánchez Robayna, 1985: 79-91). Tal y como ocurre con Lezama Lima, son muchos los aspectos del trabajo de Paz que retienen la atención de Sánchez Robayna: la confrontación entre el tiempo de la historia y el tiempo de la poesía, la meditación sobre los inestables vínculos entre palabra, yo y mundo, la incorporación del pensamiento oriental a la busca de un concepto distinto de espiritualidad y la estructuración de la tradición moderna, desde el romanticismo hasta las vanguardias, dentro de una dinámica quebrada que gobierna la alternancia entre tradición y ruptura. Todo esto forma parte del horizonte de lectura que Sánchez Robayna se forja en su comercio con la obra de Paz, pero hay algo acaso mucho más decisivo que él mismo describe, con su lucidez habitual, en otro pasaje de la conferencia de Austin citada anteriormente:

[...] la lectura de El arco y la lira y de Ladera Este, de Octavio Paz, tuvo para mí una importancia capital, tanto como, según sé, para otros poetas de mi generación. El arco y la lira pertenece a una clase de libro infrecuente en nuestra lengua: un poeta reflexiona sobre la poesía y estudia con rigor y pasión el 


\section{Gustavo Guerrero}

lenguaje, el ritmo, la imagen, las relaciones entre poesía e historia, la inspiración, la revelación, la respiración. ¿Cómo no aprender de ese libro no ya a meditar sobre algunas cuestiones esenciales sino sobre lo que Paz llama la lección moderna del poema crítico? ¿Cómo no aprender, en fin -y no es menos importante que lo anterior-, el diálogo de poesía y pensamiento, la continuidad entre ambos: el poeta que escribe prosa crítica no en mundos incomunicados sino como dos formas que dialogan y se funden hasta hacerse, con frecuencia, indistinguibles? (Sánchez Robayna, 1999: 189).

Siguiendo a Paz, Sánchez Robayna ve en esta pasión crítica, que recorre por igual pensamiento y poesía, una de las claves de la modernidad y de la condición del artista moderno que no solo se define como una conciencia activa dentro del propio proceso creador, sino que constantemente ilumina con su escritura y su lectura la obra de los demás. El recurso a una cierta reflexividad, que va adquiriendo una presencia cada vez mayor a partir de Palmas sobre la losa fría (1989) con el surgimiento de un yo que se mira en el espejo del tiempo y la experiencia, representa una de las instancias más visible del impacto de las ideas del mexicano en la génesis de la poética del canario. Aquellas «ráfagas-hendeduras» que este último veía en los versos de Pasado en claro como instantáneas que traen al poema distintos momentos del pasado y los ponen a dialogar con el presente de la escritura (Sánchez Robayna, 1985: 81), se interponen en muchas de sus composiciones de los años ochenta y noventa hasta alcanzar sin duda alguna un punto culminante en El libro, tras la duna (2000-2001), por entonces la expresión más lograda de su poética.

Pero quizás sea aún más importante ver la impronta de la pasión crítica paciana en la ingente labor que Sánchez Robayna desarrolla como intelectual con la fundación de la revista Syntaxis en Tenerife, en 1983, con las numerosas ediciones que saca a la luz y con los incontables artículos, notas y ensayos que publica a lo largo de las décadas siguientes. Tal como lo hace Paz desde México, Sánchez Robayna construye, desde su isla, no solo una versión del mundo poético canario, sino una versión canaria de la poesía del mundo donde alternan, entre otras, figuras como la de San Juan de la Cruz, Leopardi, Mallarmé, Tomás Morales, Paul Valéry, Domingo López Torres, Wallace Stevens, Pedro García Cabrera, Paul Celan, José Ángel Valente e Yves Bonnefoy. El descentramiento y reajuste de las jerarquías que se opera con este ejercicio abierto de la lectura, desplaza una vez más los ejes de las geografías culturales y hace posible otras interpretaciones del paisaje literario actual que cuestionan la imposición de una tradición y un sentido único en la evolución y la valoración de las prácticas artísticas y literarias. No creo que haga falta evocar aquí los debates y polémicas que esta actitud le acarrea a nuestro poeta, sobre todo después de la publicación de la antología panhispánica Las ínsulas extrañas (2002). Lo esencial es destacar el rol que desempeña Octavio Paz como paradigma latinoamericano del intelectual y el poeta moderno cuya misión es la de hacer las veces de un subversivo agente de enlace entre pasado, presente y futuro, entre nosotros y los otros, entre el aquí y el allá. A su imagen y semejanza, Sánchez Robayna no solo selecciona, estructura y revisa incesantemente el corpus de la poesía canaria antigua y moderna, insisto, sino que lo pone a conversar con el que va elaborando simultáneamente de la poesía española, latinoamericana, europea, occidental y no occidental. La modernidad de América Latina, como modernidad periférica al fin, para decirlo a la manera irónica de Beatriz Sarlo, es impensable sin este tipo de intervenciones, apropiaciones y reconstrucciones críticas, que son como una forma de marcar la diferencia de una 
cultura y afirmar su centralidad y su independencia. No es un secreto que Paz es, junto a Jorge Luis Borges, uno de los protagonistas más destacados de dicha estrategia crítica en el continente. Pero acaso ninguna literatura moderna de aquel lado del Atlántico la ha llevado a la práctica tan sistemáticamente como la brasileña y quizás nadie con la radicalidad, la creatividad y la osadía del poeta, crítico, traductor Haroldo de Campos.

\section{Haroldo de Campos: de la transcreación}

En La luz negra, junto a los ensayos que dedica a Lezama Lima y a Paz, Sánchez Robayna escribe unas páginas rigurosas y brillantes sobre el brasileño, que no esconden la fascinación que siente por su obra (Sánchez Robayna, 1985: 93-110). Miembro fundador del grupo Noigandres, teórico y militante del movimiento de la poesía concreta, a Haroldo de Campos se le presenta como el poeta que se adelanta hasta los límites de la aventura moderna, un explorador de lo extremo cuya osadía lo incita a llevar a sus últimas consecuencias las ideas inscritas en los proyectos de Mallarmé, Pound, Joyce, Yeats y algunos otros: «El lenguaje es aquí una figura del mundo y una figura de sí mismo», escribe el canario (Sánchez Robayna, 1985: 94). Proliferantes, proteicos, irreverentes y, sin embargo, a menudo de una profundidad y una precisión incontestables, los textos de Haroldo de Campos se alzan efectivamente como unos extraños objetos verbales que tratan de agotar todas las posibilidades materiales e inmateriales que nos brindan las palabras. El joven Sánchez Robayna presta una atención especial al trabajo que efectúa sobre los aspectos visuales y sonoros del signo, tan evidente en los ejercicios del taller de poesía concreta, y lo tiene sin lugar a duda muy presente a la hora de componer y plasmar el diseño de sus propios poemas en la verticalidad de la página, haciéndolos avanzar con un dinamismo particular a través de un movimiento regido por afinidades rítmicas y fonéticas. Pienso en esa pulida joya que es la «Retama» en el poemario La roca o aun en los versos finales de El libro, tras la duna.

En Haroldo de Campos, Sánchez Robayna vuelve a encontrarse además con uno de los tópicos más obsesivos y recurrentes de su imaginario: la reversible metáfora del texto del mundo, que nos recuerda, con Mallarmé, que todo existe para acabar en un libro y/o, con Borges, que la realidad puede ser concebida como ese interminable volumen que nunca acabaremos de leer. Galaxias (1984), el poema infinito del brasileño al que nuestro poeta dedica uno de los ensayos de La sombra del mundo (Sánchez Robayna, 1999: 77-83), quiere encarnar dicha totalidad con su escritura multilingüe, mestiza, fragmentaria, visual y musical. Sánchez Robayna celebra su ambición, su alto riesgo, y lo describe justamente como la más lograda superposición de texto y mundo en el ámbito de la poesía contemporánea. Vale la pena citar su conclusión:

Bajo el peligro de parafrasearme, no tengo más remedio que transcribir aquí una breve reflexión sobre Galaxias escrita hace algún tiempo: «Galaxias: no poesía en la prosa, sino prosa minada. Disrupción de la prosa y, finalmente, abolición de las fronteras; movilidad de la escritura: escenificación y representación textual». Añadiré ahora: uno solo de los fragmentos galácticos contiene Galaxias en su totalidad. Como en la jornada única del Ulises de Joyce, que es todos los días (y que hizo a Borges escribir: «En un día del hombre están los días / del tiempo») como un solo ready-made de Duchamp contiene todos 


\section{Gustavo Guerrero}

los ready-made (y cuyo sentido estaba, justamente, no en la fácil repetición o multiplicación manierista, sino en su número limitado o restringido); como, en fin, en la reflexión de Friedrich Schlegel en Atheäeum: «en poesía, cada totalidad es un fragmento, cada fragmento una totalidad»; como en ellos, en efecto, un solo fragmento galáctico - monadológico, aislado: un arabesco grabado en una página en blanco- es todas las Galaxias (Sánchez Robayna, 1999: 83).

Hay que contextualizar, sin embargo, esta pulsión de totalidad en el marco de las estrategias modernas de una cultura y una literatura brasileñas que, como es sabido, convierten con Andrade al caníbal y al canibalismo en los símbolos de la voracidad con que lo americano se apropia críticamente del legado de Occidente.

La poesía concreta pensó brasileñamente una nueva poética nacional y universal, un planetario de signos en rotación cuyos puntos-eventos se llamaban (como índices topográficos) Mallarmé, Joyce, Apollinaire, Pound, cummings, u Oswald de Andrade, João Cabral de Melo Neto (De Campos, 2000: 16),

señala Haroldo de Campos en De la razón antropofágica: diálogo y diferencia de la cultura brasileña, uno de los ensayos claves del pensamiento crítico latinoamericano del siglo XX. En él, expone su visión del escritor moderno del continente como una suerte de bárbaro alejandrino tocado por el apetito insaciable de devorar y de reescribir todas las literaturas del mundo en una nueva dimensión planetaria. Galaxias, que se publica en esos años, forma parte del mismo proyecto de descentramiento, afirmación y reestructuración, así como también la impresionante labor de traducción que desarrolla De Campos, llevando al idioma brasileño obras clásicas (y menos clásicas) del francés, alemán, japonés, griego, inglés, hebreo y chino, entre otras lenguas.

Dentro de esta línea de acción y pensamiento, nada expresa mejor su idea de la literatura mundial como un sideral laboratorio de vasos comunicantes que es la noción de transcreación. Con ella, siguiendo a Pound, a Jakobson y a Benjamin, insiste en el carácter crítico y creativo de cualquier traducción literaria en tanto reescritura, y además nos invita a reeditar el sueño universalista ilustrado de una República de las Letras, imaginando una vasta zona de contacto entre todas las literaturas que se comunicarían y se mezclarían gracias a la libre circulación de las versiones y reversiones de sus textos (De Campos, 2009).

El peso cada vez mayor que ha ido adquiriendo la práctica de la traducción en la obra de Sánchez Robayna a través de los últimos treinta años, no es ajeno, a mi modo de ver, ni a este ejemplo ni a este ideal. Como bien escribe José Francisco Ruiz Casanova:

Para el autor, la obra se constituye como un todo en el que la poesía, las versiones de autores extranjeros, los estudios filológicos, las críticas literarias y los diarios establecen entre sí corrientes de comunicación y correspondencias internas que espejean unos textos en otros (Ruiz Casanova, 2012: 28).

Plenamente integradas así en su quehacer, con el mismo estatuto que los poemas o los ensayos, las numerosísimas traducciones realizadas por el canario individualmente, o en el seno del Taller de Traducción Literaria de la Universidad de la Laguna, dan fe de una pasión transcreativa y de una avidez cultural no inferiores a las del vindicativo e insaciable maestro brasileño. Como él, nuestro poeta canario ha ido componiendo una rica biblioteca traducida (donde destacan, por cierto, varios 
libros de poesía del propio Haroldo de Campos) que esboza una concepción, una idea de la Weltiteratur desde las islas y proyecta la totalidad virtual que la constituye dentro de un orbe poético y literario específico, que no es igual al que podemos descubrir desde otros lugares ni otros tiempos del planeta. En fin, last but not least, acaso el rasgo más importante que los une es ver en el acto de traducir una reversible forma de escritura/lectura y una práctica política y cultural que permite hacer explícita no ya la cerrazón sino la vocación dialógica de la diferencia.

Creo que, como lo han tratado de mostrar estas líneas, lo americano o, si se prefiere, lo latinoamericano en la obra de Andrés Sánchez Robayna no está solo (ni tanto) en una estilística, ni en una temática, ni en una poética determinadas, aunque de todo ello hay en la relación que lo une a José Lezama Lima, Octavio Paz y Haroldo de Campos. Más decisivo es, en mi sentir, su modo de concebir el quehacer intelectual moderno como una manera de cultivar justamente esa diferencia dialógica y de construir una imagen de la totalidad que le pertenezca y se corresponda con su idea del mundo. El poeta, el crítico, el traductor, el editor de antologías y de revistas no ha hecho otra cosa a lo largo del medio siglo en que ha ido borrando fronteras y moviendo los lindes de las geografías culturales heredadas de nuestra larga historia colonial. Aún estamos lejos de ver surgir ese espacio común de la poesía escrita en español a ambos lados del Atlántico que Sánchez Robayna postulaba, en 2005, como el único susceptible de ofrecer una valoración completa de la producción literaria en nuestro idioma (Sánchez Robayna, 2005: 16); aún estamos lejos también de un ideal cosmopolita y transcreativo de la literatura mundial que acepte la diversidad y el relativismo, la pluralidad que existe en nuestros mapas descentrados. Pero la obra admirable de este canario tiene hoy por hoy entre sus muchos y variados méritos el de adelantarnos un buen trecho en el camino que, un día, ha de llevarnos hasta allí.

\section{Bibliografía}

ARJONA, D. (2009): «Andrés Sánchez Robayna: los insulares tenemos una pulsión del espacio como frontera», El Cultural, Revista de Letras http://www.elcultural.com/revista/letras/AndresSanchez-Robayna/25710 (última consulta, 15-08-17).

CruZ-Malave, A. (1994): El primitivo implorante: el sistema poético del mundo de José Lezama Lima. Amsterdam/Atlanta, Rodopi.

DE CAMPOS, H. [1980] (2000): De la razón antropofágica: diálogo y diferencia de la cultura brasileña. Buenos Aires, Siglo XXI.

- (2009): «Da Transcriação. Poética e semiótica da operação tradutora», Cuadernos Viva Voz. Belo Horizonte: FALE/UFMG, 128-160.

MEREDIS, E.M. (2009): «De Insulis o más ínsulas que se repiten: Canarias, Cuba y el Atlántico Hispano», Revista Iberoamericana LXXXV/228, pp. 865-884. 
182 Tropelías. Revista de Teoría de la Literatura y Literatura Comparada, 29 (2018) Gustavo Guerrero

Mignolo, W.D. (2003): Historias locales, diseños globales: colonialidad, conocimientos subalternos y pensamiento fronterizo. Madrid, Akal.

QuiJANo, A. (2007): «Coloniality and Modernity», Cultural Studies 21/2-3, pp. 155-167.

Rojo, J. A. (2002): «Una antología agita las aguas de la poesía», El País, Madrid, 14/09/02 https://elpais.com/diario/2002/09/14/cultura/1031954401_850215.html (última consulta, 30/11/17).

Ruiz Casanova, J. F. (2012): «Introducción», en A. SÁnchez Robayna, El espejo de tinta (antología 1970-2010), edición crítica de J. F. RuIz Casanova, Madrid, Cátedra.

SÁnchez Robayna, A. (1985): La luz negra. Madrid, Ediciones Júcar. (1993): Silva gongorina. Madrid, Cátedra.

(1994): «Canarias y América en la literatura de dos siglos», Estudios Canarios, Anuario del Instituto de Estudios Canarios XXXVIII, pp. 49-60.

- (1999): La sombra del mundo. Valencia, Pre-textos. (2002): Días y mitos, diarios 1996-2000. México/Madrid, Fondo de Cultura Económica. (2005): «Una versión de la poesía hispánica contemporánea», en A. SÁNCHEZ RoBAYNA y J. Doce, eds., Poesía hispánica contemporánea, ensayos y poemas. Barcelona, Galaxia Gutenberg/Círculo de Lectores, pp. 13-42. 